are mainly elicited by speech. A further reason for recording abnormal nerve-signs as distinct from the developmental signs is that the separate nerve-signs may to some extent be removed in detail by training, while the gradual removal of each defect in movement and Dalance indicates the improvement effected by training and shows the teacher certain points requiring daily attention. I have spoken of a clinical examination for the purpose of mental classification ; beyond this, of course, a medical examination is needed on the ordinary points of bealth and freedom from disease. It may be well to draw attention to the frequency of deafness and naso-pharyngeal obstruction, defect of the eyes, skin, teeth, and glands, in cases of mental defect; conversely, I would draw attention to the frequency of mental defect in cases brought under treatment for the conditions just mentioned. It has been shown in the published report that all cases with any developmental defect are more delicate than others, their tissues fall into low nutrition under adverse environment (this fact is specially marked in the case of girls under all circumstances). I cannot but think that the boarding-out of such children under the Poor-law, as has been proposed, will lead to difficulties in the future. The diagnosis, classification, and management of children and adults with mental dulness and weakness is a subject that has recently attracted much public attention, while our State departments have recognised that provision for the care of such cases is necessary. The -subject appears to call for due consideration from our profession, especially now that educational questions are so widely discussed and some educational bodies are seeking assistance from medical men.

After receiving evidence from the early part of the inquiry of the Committee on School Children, the Royal Commission on the Blind, \&c., reported in 1889 "that with regard to 'feeble-minded' children they should be separated from ordinary scholars in public elementary schools in order that they may receive special instruction, and that the attention of school authorities be particularly directed towards this object." The London School Board has provided day classes of special instruction at twenty-four centres, where over 1000 children, dull, backward, or feebly gifted mentally, are taught; this is apart from the classes for the blind and dumb carried on under the Sducation Act of 1893. Clearly for such cases further industrial training is needed when they leave school at fourteen years of age.

The subject here dealt with is a large one and presents many aspects, especially in individual cases which must be dealt with according to circumstances. The census shows that 24 per cent. of the population are of school age, and the examination of 100,000 children seen in schools showed that about 1 per cent. are distinctly below the normal in mental or physical conditions, which may best be dealt with in early ife and who are improvable under early and continuous 'sraining.

Prince of Wales-terrace, Kensington Palace, $\mathrm{W}$.

\section{THE TREATMENT OF EMPYEMA BY A VALVULAR TUBE.}

\section{BY W. MENZIES HUTTON, M.D., F.R.C.S. EDIN}

THE results obtainable by treating empyema by incision and drainage with an ordinary tube are often far from satisfactory. Many cases certainly heal up fairly well, but in a large number of cases healing, if obtained, is only after many weeks, and then we get considerable falling in of the chest wall and diminished expansion of the lung on that side. Cases are continually occurring in which Estlander's operation becomes necessary, and then even healing does not always follow. Nor are these unsatisfactory results to be wondered at seeing the usual methods of treatment are only to provide free exit of pus without attempting to aid in the expansion of the lung. In cases following pneumonia, influenza, and other acute affections good results are got by the ordinary methods of treatment. In these, however, even when healing bas resulted in two or three weeks, I have found in a number of cases examined, even after months, that there remained an appreciable falling in of the chest wall with diminished expansion of the lung on the affected side. To understand how a ralfular tube will enable the lung to expand we must have clearly before us the condition of affairs when there is an opening into the pleural sac. The lung is collapsed and the respiratory movements of the lung are reversed. With inspiration we have still further collapse of the lung by air rushing in at the opening into the pleural sac and by the expanding lung drawing air out of the collapsed one. With expiration, on the other hand, air is expelled from the healthy lung and distends the collapsed one. This is only slightly seen with ordinary expiration, but with forced expiratory acts, such as coughing, it is very evident. This can be proved by removing a portion of the chest wall in animals, and was demonstrated on the human subject in Germany, where it was necessary to remove a portion of the chest wall with a tumour. Here with each inspiration the collapsed lung was seen to diminish still further and with a cough the lung filled the pleural sac. In animals a hernia of the lung may even result from excessive expiratory acts. It is seen also just after opening an empyema: with inspiration the discharge lessens or even ceases, and with expiration it is violently expelled. Now if we introduce a tube with a valve attached we see that with expiratory acts air and discharge are expelled, but with inspiration the valve closes and no air gets back into the pleural sac, and the lung remains so far expanded and is ready to expand still more with each succeeding expiratory effort. In short, the lung keeps what it gains. I have tried several kinds of valves and apparatus and have now got one which works admirably. It consists of a large indiarnbber tube with a rectangular rubber flange about 5 in. long and 4 in. broad. It is of sheet rubber about 2 in thick. The tube is just long enough to go through the chest wall. Into this tube is fitted a right-angled piece of glass tubing to which is attached a large-sized indiarubber drainage-tube about $6 \mathrm{in}$. long, and to this a duck-bill valve made of fine indiarubber is attached. This valve is encased by a glass tube which protects it from pressure. Between the flange of the indiarubber tube and the skin is inserted a piece of gutta-percha tissue somewhat larger than the flange. This sticks to the flange and to the skin and assists in preventing air getting in by the side of the flange. The opening in the chest wall should be made in the mid-axillary line at the level of the sixth rib, as this is the part to which the lung last expands. A dependent opening is not necessary and may be disadvantageous. When we are dealing with the pleural sac we have a piston arrangement by which the lung with expiratory efforts expels the discharge. I have tried the apparatus in cases where the opening bad been made posteriorly or anteriorly, and what occurs is this-the lung comes out to the opening and blocks it, while a cavity remains at the lateral aspect of the chest. After the opening has been made the indiarubber tube is introduced, and the flange lies against the skin with the gutta-percha tissue between. Pads of wool are placed over the flange, which is fixed by a domette bandage to the chest. The large drainage-tube with the valve is slid over the bent glass tube and the valve end is carried round the chest to the front of the abdomen, where it is enveloped in wool to absorb the discharge, and this is retained in position by a binder. When the flange has been applied and the valve attached one can demonstrate the valve working. When the patient coughs air and discharge are expelled between the lips of the valve, and when inspiration occurs the lips of the valve are seen to close tightly. If now the lips are opened by inserting a probe between them air is heard to rush in, showing that more or less of a vacuum has been produced within the pleural sac. I would claim for this apparatus that it is simple and works admirably ; that it hastens the expansion of the lung without causing any traction on the lung, as do syphon methods of drainage; and that it is safe and comfortable to the patient, who usually expresses himself easier after it is applied, as it enables him to breathe and cough much more easily. After even twenty.four hours the respirations are much reduced in frequency. The valvular tube has a further distinct advantage, in so far that it prevents air going into the pleural sac and so prevents sepsis, which frequently occurs in empyema. The discharge will be seen often after a day or two to become simply serous. There is also a great saving of dressing, as all the discharge escapes into the wool over the abdomen, and a nurse can easily change this. The flange does not require to be touched every day. Once every four days is usually sufficient for the wound itself to be looked to. For this purpose the tube is removed and, of course, air gets into the pleural 
sac, but as soon as the apparatus is re-applied a few coughs again expand the lung. As the lung expands the parietal and visceral pleuræ become adberent and obliterate the cavity. In acute cases the expansion may be compiete in two or three days; in more chronic cases it may take ten days or more. I have seen a lung expand after it had been collapsed for eight months. The method is suitabie for all cases except those in which a communicarion with a bronchus exists. It is rather difficult to know when complete expansion and adhesion have taken place. This can usually be determined by introducing a probe and feeling the lung. I append short notes of three cases which show the results attainable by this method.

CASE 1.-The patient was a woman aged thirty-eight years. She had an empyema which was treated in the ordinary way and apparently healed. Three months later it was found again discharging and there was a cavity which would contain about four ounces of pus. Great relief followed the application of the valve tube, especially by easing the breathing. Expansion occurred in five days there was no recurrence.

CASE 2.-The patient was a man, aged twenty-two years, suffering from phthisis and empyema. This was opened and drained in the usual way for about twelve days. Then there was no sign of closure of the cavity and the valve tube was tried. The day after the tube was applied the patient was tested as regards his breathing by a spirometer. Three days later he was again tested and had now increased his breathing capacity by ten cubic inches. The discharge had also ceased and the lung was found expanded and adherent all over except for about one inch below the wound. This I expected to close and removed the tube. Just before the valve tube was used the pulse averaged 110 and the respiration 24 per minute. The temperature was $100^{\circ} \mathrm{F}$. at night. On the second day after the pulse was 96 , the respiration 18 , and the temperature $99^{\circ}$. In this case I took out the tube a little prematurely, as some small re-accumulation occurred. The small cavity soon bealed and three months after the patient had gained $21 \mathrm{lb}$. in weight.

CASE 3. - The notes of this case were kindly sent to me by Dr. Simpson of Golspie. The patient, a young man, aged twenty-three years, tall, phthisical, came in January, 1895, with a history of pleurisy two years previously, for which he was tapped in the Edinburgh Royal Infirmary, and also received injections of tuberculin. His left chest was filled with fluid, the apex beat being nearly under the right nipple. Aspiration was done several times and about ninety ounces of pus removed. As re-accumulation rapidly took place Dr. Simpson opened into the pleural sac through the sixth interspace and inserted the valve tube on April 1st. On April 5th the discharge had entirely ceased, the tube was removed, and the wound healed in a few days. The patient made an uninterrupted recovery, and in July was able to assist in haymaking and did most of the harvest work on his father's croft. By Oct. 14th he had gained nearly 2 st. in weight and could climb a steep hill without inconvenience to his breathing.

Space forblds further examples, but I think these will show what results may be gained by this method of treatment. I believe that by it we can gain a more rapid and more complete return to the normal in acute cases; in chronic we can get the lung to expand and be useful instead of the patient being worn out by long-continued suppuration, ending often in death or requiring the subsequent performance of Estlander's operation, which, if it stops the suppuration, deprives the patient of the use of the lung. This becomes a mass of tissue of low vitality, and, I believe, forms a fit nidus for the tabercle bacillus. The tube or valve may get blocked, but I have never had any trouble from this. If it should occur the apparatus is easily cleaned. The apparatus is to be had from Messrs. Walters and Co., 69, Lambeth Palice-road, London; or Messrs. Young and Son, Forress-road, Edioburgh.

Edinburgh.

Clevedor Convalescent Home.-From the annual report of this institution, just issued, it appears that the past year has been a record one, 335 patients having been admitted. The total number of admissions since November, 1881, is stated to be 4168 . The receipts for the past year were $£ 801$ and the expenditure $£ 790$. The reserve fund account shows a balance in hand of $£ 65$.

\section{Clinital altotes:}

\section{MEDICAL, SURGICAL, OBSTETRICAL, AND THERAPEUTICAL.}

\section{NOTE ON A CASE OF RESECTION OF THE RADIUS FOR SARCOMA.}

By E. H. Douty, M.B., B.C. CAMB., ASSISTANT SURGEON TO ADDENBROOKE'S HOSPITAL, CAMBRIDGE.

THene is so little deformity in this case and the hand is so useful that I have thought it worth while to draw attention to it, as it may guide others to choose resection of the bone rather than amputation in cases of slow-growing endosteal sarcoma. The woman has fair grasping power and finds her hand useful to her in her household duties. The illustrations show (A) the state of the limb before the

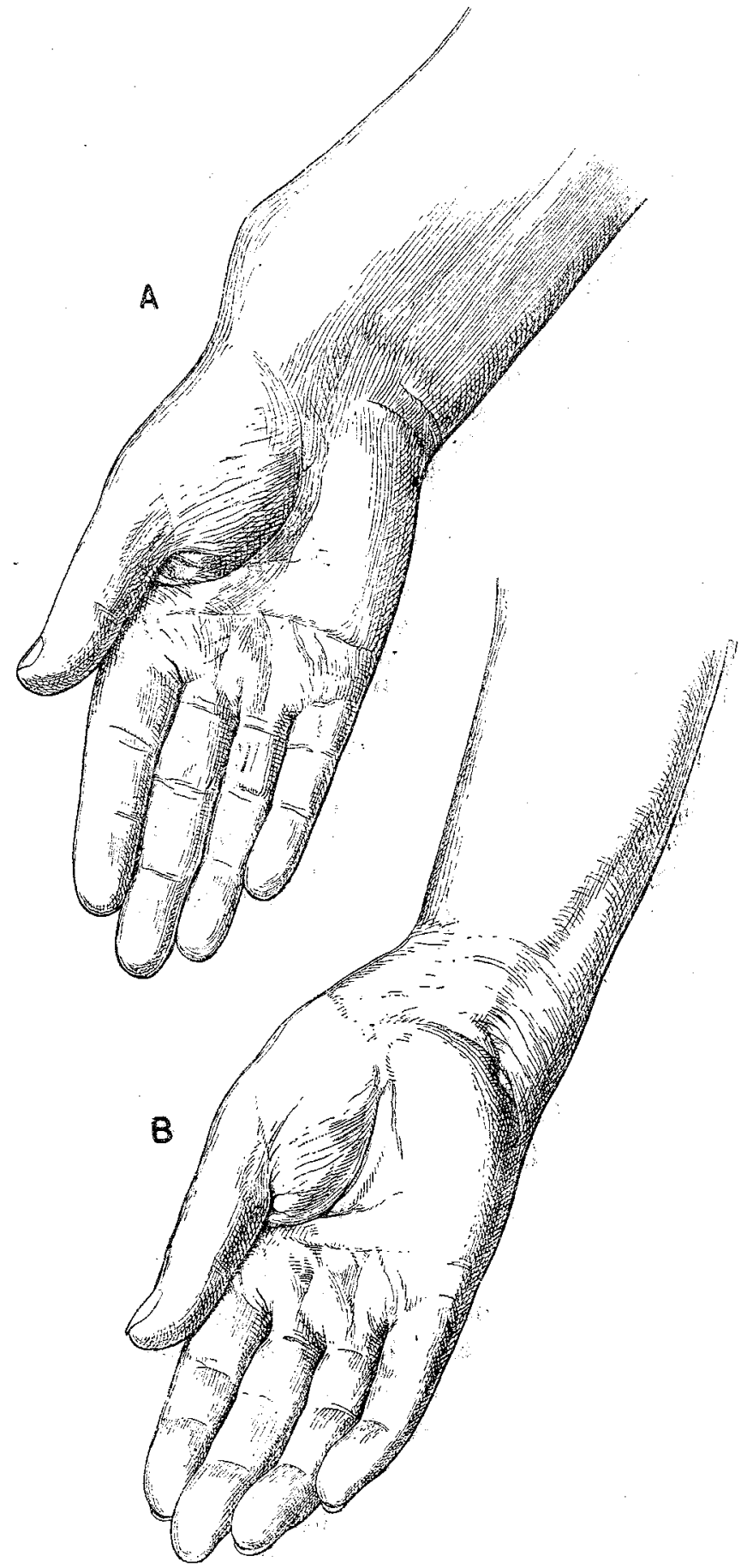

Fig. A. shows the appearance of the hand and wrist before, and Fig. B. after, the operation.

operation and (B) at the present time. The tumour pulsated in places and there was a history of eighteen months' growth. It proved to be a myeloid sarcoma. The patient was a widow, aged forty-eight years, and her personal and family history are without significance. I made a long incision over the outer aspect of the bone and extending to the midale of the metacarpus. I found the cartilages of the 